\title{
AS CIÊNCIAS SOCIAIS NA ÉPOCA DA GLOBALIZAÇÃO
}

\section{Octavio Ianni}

\section{Ruptura histórica}

A globalização do mundo pode ser vista como um processo histórico-social de vastas proporções, abalando mais ou menos drasticamente os quadros sociais e mentais de referência de indivíduos e coletividades. Rompe e recria o mapa do mundo, inaugurando outros processos, outras estruturas e outras formas de sociabilidade, que se articulam e se impõem aos povos, tribos, nações e nacionalidades. Muito do que parecia estabelecido em termos de conceitos, categorias ou interpretações, relativos aos mais diversos aspectos da realidade social, parece perder significado, tornar-se anacrônico ou adquirir outros sentidos. Os territórios e as fronteiras, os regimes políticos e os estilos de vida, as culturas e as civilizações parecem mesclar-se, tensionar-se e dinamizar-se em outras modalidades, direções ou possibilidades. As coisas, as gentes e as idéias movem-se em múltiplas direções, desenraízam-se, tornamse volantes ou simplesmente desterritorializam-se. Alteram-se as sensações e as noções de próximo e distante, lento e rápido, instantâneo e ubíquo, passado e presente, atual e remoto, visível e invisível, singular e universal. Está em curso a gênese de uma nova totalidade histórico-social, abarcando a geografia, a ecologia e a demografia, assim como a economia, a política e a cultura. As religiões universais, tais como o budismo, o taoísmo, o cristianismo e o islamismo, tornam-se universais também como realidades histórico-culturais. O imaginário de indivíduos e coletividades, em todo o mundo, passa a ser influenciado, muitas vezes decisivamente, pela mídia mundial, uma espécie de" príncipe eletrônico", do qual nem Maquiavel nem Gramsci suspeitaram.

É assim que os indivíduos e as coletividades, compreendendo povos, tribos, nações e nacionalidades, ingressam na era do globalismo. Trata-se de um novo "ciclo" da história, no qual se envolvem uns e outros, em todo o mundo. Ao lado de conceitos tais como "mercantilismo", "colonialismo" e "imperialismo", além de "nacionalismo" e "tribalismo", o mundo moderno assiste à emergência do "globalismo", como nova e abrangente categoria histórica e lógica. O globalismo compreende 
relações, processos e estruturas de dominação e apropriação desenvolvendo-se em escala mundial. São relações, processos e estruturas polarizadas em termos de integração e acomodação, assim como de fragmentação e contradição, envolvendo sempre as condições e as possibilidades de soberania e hegemonia. Todas as realidades sociais, desde o indivíduo à coletividade, ou povo, tribo, nação e nacionalidade, assim como corporação transnacional, organização multilateral, partido político, sindicato, movimento social, corrente de opinião, organização religiosa, atividade intelectual e outras, passam a ser influenciadas pelos movimentos e pelas configurações do globalismo, e a influenciá-lo. São articulações, integrações, tensões e contradições, envolvendo uns e outros, organizações e instituições, ou as mais diversas realidades sociais, de tal forma que o globalismo pode aparecer mais ou menos decisivamente no modo pelo qual se movem indivíduos e coletividades no novo mapa do mundo.

O que está em causa quando se trata de globalização é uma ruptura histórica de amplas proporções, com implicações epistemológicas que exigem reflexão. Com as metamorfoses do "objeto" das ciências sociais e a simultânea alteração das possibilidades que se abrem ao "sujeito" da reflexão, colocam-se novos desafios não só metodológicos e teóricos, mas também epistemológicos. $\mathrm{O}$ objeto das ciências sociais deixa de ser principalmente a realidade histórico-social nacional, ou o indivíduo em seu modo de ser, pensar, agir, sentir e imaginar. Desde que se evidenciam os mais diversos nexos entre indivíduos e coletividades, ou povos, tribos, nações e nacionalidades, em âmbito mundial, o objeto das ciências sociais passa a ser também a sociedade global. Muito do que é social, econômico, político, cultural, lingüístico, religioso, demográfico e ecológico adquire significação não só extranacional, internacional ou transnacional, mas propriamente mundial, planetária ou global. Quando se multiplicam as relações, os processos e as estruturas de dominação e apropriação, bem como de integração e fragmentação, em escala mundial, nesse contexto estão em causa novas exigências epistemológicas. Nesse horizonte, alteram-se as condições históricas e teóricas sob as quais se desenvolvem os contrapontos, os nexos, as simultaneidades, descontinuidades, desencontros e tensões entre dado e significado, aparência e essência, parte e todo, passado e presente, história e memória, lembrança e esquecimento, tradição e origem, território e fronteira, lugar e espaço, singular e universal. Alteram-se mais ou menos drasticamente as condições, as possibilidades e os significados do espaço e do tempo, já que se multiplicam as espacialidades e as temporalidades.

Esse o desafio diante do qual se colocam as ciências sociais. Ao lado das suas muitas realizações, são desafiadas a recriar o seu objeto e os seus procedimentos, submetendo muito do conhecimento acumulado à crítica e avançando para novas ambições. Os cientistas sociais não precisam mais imaginar o que poderia ser o mundo para estudá-lo. $\mathrm{O}$ mundo já é uma realidade social, complexa, difícil, impressionante e fascinante, mas pouco conhecida.

Já não se trata mais apenas da controvérsia modernidade e pós-modernidade, ou universalismo e relativismo, individualismo e holismo, pequeno relato e grande relato, micro teoria e macro teoria, mas também de megateoria. A envergadura das relações, processos e estruturas de âmbito mundial, com as suas implicações locais, nacionais, regionais e mundiais, exige conceitos, categorias ou interpretações de alcance global. Esse o contexto em que se elaboram metáforas e conceitos tais como: multinacional, mundial, planetário e global; aldeia global, nova ordem econômica mundial, mundo sem fronteiras, terra-pátria, fim da geografia e fim da história; desterritorialização, miniaturização, ubiqüidade das coisas, gentes e idéias, sociedade informática, infovia e internet; sociedade civil mundial, estruturas mundiais de poder, classes sociais transnacionais, globalização da questão social, cidadão do mundo e cosmopolitismo; ocidentalização do mundo, orientalização do mundo, globalização, globalismo, mundo sistêmico, capitalismo global, neoliberalismo, neonazismo, neofascismo, neosocialismo e modernidade-mundo. 
Mais uma vez, as ciências sociais revelam-se formas de autoconsciência científica da realidade social. Neste caso, uma realidade social múltipla, desigual e contraditória, ou articulada e fragmentada. São muitos, inúmeros, os estudos de todos os tipos, sobre todos os aspectos da realidade social, produzidos em todo o mundo, em todas as línguas. Há toda uma biblioteca de Babel formada com os livros e as revistas de ciências sociais que se publicam, conformando uma visão múltipla, polifônica, babélica ou fantástica das mais diversas formas de autoconsciência, compreensão, explicação, imaginação e fabulação tratando de entender o presente, repensar o passado e imaginar o futuro (Comissão Gulbenkian, 1996; Wallerstein, 1991; Ianni, 1997; Pennycook, 1994).

\section{Enigmas teóricos}

A rigor, são vários os enigmas históricos e teóricos suscitados pela globalização, envolvendo inclusive problemas epistemológicos importantes. No âmbito da globalização, ou do globalismo visto como uma totalidade histórico-teórica, reabrem-se os contrapontos, as continuidades e as descontinuidades, sintetizados em noções tais como: sujeito e objeto do conhecimento, parte e todo, passado e presente, espaço e tempo, singular e universal, micro teoria e macro teoria. Estes e outros problemas envolvem novos desafios e outras perspectivas quando se trata de refletir sobre as relações, os processos e as estruturas, bem como as formas de sociabilidade e os jogos das forças sociais, que desenham as configurações e os movimentos da sociedade global.

Uma parte importante das controvérsias que abalam, traumatizam e fertilizam as ciências sociais na época do globalismo desemboca no desenvolvimento de estudos que podem ser classificados de "metateóricos". Realmente, multiplicam-se os estudos de História, Sociologia, Antropologia, Economia, Política, Geografia, Demografia, Ecologia e outros, contribuindo para interpretações abrangentes e integrativas, ou propriamente metateóricas.
Ocorre que a globalização, como totalidade não só abrangente e integrativa, mas complexa, fragmentária e contraditória, subsume crescentemente indivíduos e coletividades, povos e tribos, nações e nacionalidades, grupos sociais e classes sociais, partidos políticos e movimentos sociais, etnias e raças, línguas e religiões, culturas e civilizações. Sem esquecer que a recíproca também é verdadeira, já que estas diversas e múltiplas realidades se constituem como determinações da globalização, globalidade ou globalismo. Mais uma vez, e sempre, recoloca-se a dialética parte e todo, tanto quanto singular e universal.

Vale a pena examinar algumas das breves "definições" de globalização presentes em estudos de cientistas sociais. Há congruências e disparidades entre elas, mas cabe registrar a unanimidade com que se reconhece a problemática.

Esse é um tema importante para o historiador. Como diz Grew (1993, p. 228):

Poucas afirmações provocam tão pequenas controvérsias como a de que os seres humanos estão hoje em contato uns com os outros em todo o mundo como nunca na história. A lista de exemplos tornou-se uma litania: a comunicação instantânea da informação, a cultura universal de estilos e experiências, o alcance mundial de mercados e mercadorias, os produtos compostos de partes oriundas de diferentes continentes. $\mathrm{E}$ a referência à aldeia global tornou-se um clichê que poucos contestam.

Também a Antropologia debruça-se sobre o tema:

A idéia de que o mundo pode ser visto como um pequeno viveiro ligado pela abrangente força da mídia e do capitalismo internacional é o pano de fundo que serve de base ao empenho de muitos intelectuais, à atividade comercial e às diretrizes de governo na atualidade. Uma das coisas que a tecnologia realmente revoluciona é a escala, ou são as escalas, em que operam as relações sociais. (Moore, 1996, p. 7)

O sociólogo coloca-se o mesmo desafio: "Globalização diz respeito àqueles processos pelos quais os povos do mundo são incorporados em uma sociedade mundial, uma sociedade global." (Albrow,1990, p. 9). E o cientista político também participa do debate:

Globalização diz respeito à multiplicidade de relações e interconexões entre Estados e sociedades, conformando o moderno sistema mundial. Focaliza o processo pelo qual os acontecimentos, decisões e atividades em uma parte do 
mundo podem vir a ter conseqüências significativas para indivíduos e coletividade em lugares distantes do globo. (McGrow, 1992, p. 23)

Nesse "congresso" de cientistas sociais está presente inclusive o economista:

A economia global é o sistema gerado pela globalização da produção e das finanças. A produção global beneficia-se das divisões territoriais da economia internacional, jogando com as diferentes jurisdições territoriais, de modo a reduzir custos, economizar impostos, evitar regulamentos antipoluição e controles sobre o trabalho, bem como obtendo garantias de políticas de estabilidade e favores. A globalização financeira construiu uma rede eletrônica conectada 24 horas por dia, sem controles. As decisões financeiras mundiais não estão centralizadas nos Estados, mas nas cidades globais Nova York, Tóquio, Londres, Paris, Frankfurt ， estendendo-se por computadores para o resto do mundo. (Cox, 1994, p. 48)

Note-se que as "definições" de globalização nem sempre se distinguem pela originalidade. Algumas são um tanto vagas, ao passo que outras dedicam-se a precisar aspectos ou ângulos. Mas a maioria reconhece a novidade dessa problemática, desafiando a pesquisa e a teoria nas ciências sociais.

Aliás, já é notável a quantidade e a qualidade dos estudos sobre a globalização, ou os seus diferentes aspectos, que podem ser classificados de metateóricos. Uns são monográficos e outros ensaísticos, assim como há os que são principalmente descritivos, ao lado dos interpretativos. Além disso, destacam-se os que são críticos, no sentido de que se debruçam sobre os nexos e os movimentos da realidade, buscando desvendar a sua constituição e a sua dinâmica, ao lado dos seus impasses e das suas contradições. Mas também multiplicam-se os que se dedicam a fundamentar e explicitar prognósticos, diretrizes ou objetivos convenientes para governos, corporações, organizações multilaterais, movimentos sociais. No que se refere à orientação teórica, cabe reconhecer que há estudos elaborados em termos evolucionistas, funcionalistas, marxistas, weberianos, estruturalistas e sistêmicos, entre outros. Nem sempre são "ortodoxos" quanto a esta ou aquela orientação, já que há ecletismos diversos, umas vezes criativos e outras empobrecidos.
Sim, a globalização cria vários enigmas mais ou menos importantes para as ciências sociais. Vale a pena examinar alguns desses enigmas, ainda que de forma breve.

Primeiro, a realidade social, ou o "objeto" das ciências sociais, revela-se diferente, novo ou surpreendente. Revelase simultaneamente mundial, nacional, regional e local, sem esquecer o tribal. Muito do que é particular revela-se também geral. O indivíduo e a coletividade constituem-se na trama das formas de sociabilidade e no jogo das forças sociais em desenvolvimento em âmbito global. Muito do que pode ser identidade e alteridade, nação e nacionalidade, ocidental e oriental, cristão e islâmico, africano e indígena ou soberania e hegemonia revela-se constitutivo das formas de sociabilidade e do jogo das forças sociais que se desenvolvem em âmbito simultaneamente global, regional, nacional, tribal e local. Nesse sentido é que a globalização, a globalidade ou o globalismo se constitui como um objeto diferente, novo ou surpreendente das ciências sociais. Aí se desenvolvem relações, processos e estruturas demarcando as configurações e os movimentos da sociedade global. Uma sociedade na qual se inserem dinâmica e decisivamente os indivíduos e as coletividades, os grupos sociais e as classes sociais, os gêneros e as raças, os partidos e os sindicatos, os movimentos sociais e as correntes de opinião pública; uma sociedade na qual tanto se multiplicam como se dissolvem os espaços e os tempos.

Segundo, "o acervo teórico das ciências sociais" revela-se insatisfatório, carente de significado, exigindo reelaboração ou mesmo dependente de novos conceitos, categorias ou leis. São muitos os recursos teóricos acumulados pelas várias teorias da realidade social que se mostram problemáticos, inadequados ou carentes de complementação. Ocorre que, em sua maioria, os conceitos, as categorias e as leis são construídas tendo como referência a "sociedade nacional". Essa realidade tem sido vista a partir de noções científicas mais ou menos sedimentadas, tais como: sociedade civil e Estado, Estado/nação e soberania e hegemonia, povo e cidadão, grupo social e classe social, classe social e lutas de classe, partido político e sindicato, indivíduo e sociedade, natureza e sociedade, identidade e alteridade, cooperação e divisão 
do trabalho, ordem e progresso, democracia e ditadura, nacionalismo e imperialismo, tribalismo e nacionalismo, cultura e tradição, mercado e planejamento, reforma e revolução, revolução e contra-revolução, revolução nacional e revolução social, relações internacionais e geopolíticas, geopolítica e guerra, capitalismo e socialismo. Em geral, são noções construídas, aceitas, debatidas e mais ou menos sedimentadas, tendo como referência principal a sociedade nacional. Ainda que algumas dessas noções extrapolem essa realidade, como ocorre com diversas, é inegável que todas têm como parâmetro a sociedade nacional. Por isso cabe refletir sobre a" sociedade mundial", em toda a sua originalidade e complexidade, tendo em vista interpretar as suas configurações e os seus movimentos. Daí a importância de noções, metáforas ou conceitos como: mundialização, planetarização, globalização, mundo sem fronteira, aldeia global, fábrica global, shopping center global, divisão transnacional do trabalho e da produção, estruturas mundiais de poder, desterritorialização, cultura global, mídia global, sociedade civil mundial, cidadão do mundo, mercados mundiais, infovia, internet, metahistória, metateoria.

Terceiro, são numerosos os estudos de "orientação multidisciplinar". Em lugar de se lançarem em perspectivas estritas, sejam elas sociológica, econômica, política, antropológica ou outra, lançam-se com base nas sugestões e conquistas propiciadas por diversas ciências sociais. A originalidade e a complexidade da globalização, no seu todo ou em seus distintos aspectos, desafiam o cientista social a mobilizar sugestões e conquistas de várias ciências. Acontece que a globalização pode ser vista como um vasto processo não só político-econômico, mas também sociocultural, compreendendo problemas demográficos, ecológicos, de gênero, religiosos, lingüísticos e outros. Ainda que a pesquisa privilegie determinado ângulo de análise, está continuamente desafiada a levar em conta outros aspectos da realidade, sem os quais a análise econômica, política, sociológica, ecológica ou outra resulta em abstrações carentes de realidade, consistência ou verossimilhança.
Quarto, são muitos os estudos que se apóiam necessariamente no "método comparativo". Mais do que nunca, diante da problemática da globalização, o cientista social é levado a realizar comparações mais ou menos complexas, buscando que sejam rigorosas. $\mathrm{Na}$ medida em que a globalização abre um vasto e complexo cenário à observação, pesquisa e análise, o cientista social é levado a mapear ângulos e tendências, condições e possibilidades, recorrências e descontinuidades, diversidades e desigualdades, impasses e rupturas, desenvolvimentos e retrocessos, progressos e decadências. São muitos os processos e as estruturas presentes, ativos, visíveis ou subjetivos, no vasto e complicado palco constituído com a globalização do capitalismo, como modo de produção e processo civilizatório. Daí a importância do método comparativo, como uma forma experimental, uma espécie de experimento mental, ideal ou imaginário.

Quinto, mais uma vez reabre-se a controvérsia "presente e passado", e vice-versa. Com a globalização, tanto se criam novos desafios e novas perspectivas para a interpretação do presente, como se descortinam outras possibilidades de interpretar o passado. A partir dos horizontes da globalização, o passado pode revelar-se ainda pouco conhecido, enigmático ou mesmo carente de novas interpretações. É como se uma nova luz permitisse clarificar com outras cores o que parecia desenhado, assim como desvendasse traços, movimentos, sons e cores que não se havia percebido quando o patamar podia ser nacionalismo, colonialismo, imperialismo, internacionalismo ou outro. Com as novas perspectivas, são várias as realidades e interpretações que podem ser repensadas. Torna-se possível reavaliar o alcance e o significado da acumulação originária, do mercantilismo, colonialismo e imperialismo, tanto quando do nacionalismo e tribalismo. Também se torna possível repensar outras realidades antigas e recentes: islamismo e cristianismo, Oriente e Ocidente, ocidentalização do mundo, orientalização do mundo, africanismo, indigenismo, transculturação.

Sexto: aqui se coloca novamente o dilema do "sujeito do conhecimento". Ele precisa rever as suas posições 
habitualmente adotadas na análise da problemática nacional. Posições que parecem estabelecidas, cômodas ou estratégicas precisam ser revistas ou radicalmente modificadas. Quando se trata da problemática global, o sujeito do conhecimento é desafiado a deslocar o seu olhar por muitos lugares e diferentes perspectivas, como se estivesse viajando pelo mapa do mundo. As exigências da reflexão implicam a adoção de um "olhar desterritorializado", capaz de mover-se do indivíduo à coletividade, caminhando por povos e nações, tribos e nacionalidades, grupos e classes sociais, culturas e civilizações. Um olhar desterritorializado movendo-se através de territórios e fronteiras, atravessando continentes, ilhas e arquipélagos.

São vários os enigmas com os quais se defrontam as ciências sociais quando se trata de surpreender os movimentos e as configurações da sociedade mundial. Se é verdade que as ciências sociais nascem com a nação, talvez se possa afirmar que elas renascem com a globalização (Ortiz, 1994; Robertson, 1992; Hettne, 1995; Durand, Levy e Retaille, 1993).

\section{Metateorias}

Tomados em conjunto, os estudos sobre a globalização podem ser classificados em" sistêmicos" e "históricos". As suas linguagens podem ser muito diversas, envolvendo noções que parecem díspares: transnacionalização, mundialização, planetarização, globalização ou globalismo; assim como nova ordem econômica mundial, mundo sem fronteiras, aldeia global, terra pátria, capitalismo mundial, políticos globais, história global, cultura global, modernidade-mundo, ocidentalização do mundo e outras. Inclusive podem distinguir-se os estudos em termos de orientações teóricas: evolucionismo, funcionalismo, marxismo, weberianismo, estruturalismo sistêmico ou outro. A despeito dessas e outras diferenças ou convergências, em geral significativas, cabe reconhecer que os estudos sobre globalização tendem a ser predominantemente "sistêmicos" ou" históricos".
Em geral, os estudos sistêmicos privilegiam as relações internacionais, a interdependência das nações, a integração regional, a geoeconomia e a geopolítica. Aí predomina a preocupação com as zonas de influência, os blocos de nações, os espaços geográficos, as hegemonias, as articulações dos mercados, a divisão transnacional do trabalho e da produção, a fábrica global, o shopping center global, as redes de internet, o fim da geografia e o fim da história, entre outras articulações, malhas, redes, interdependências ou traçados do mapa do mundo. Muito do que são as relações, os processos e as estruturas tecendo os diversos níveis e segmentos da globalização são descritos e interpretados em termos sistêmicos.

São principalmente sistêmicos os relatórios, diagnósticos e prognósticos de que se servem as corporações transnacionais, os órgãos da Organização das Nações Unidas (ONU), os técnicos do Fundo Monetário Internacional (FMI), do Banco Mundial (BIRD Banco Internacional de Reconstrução e Desenvolvimento), da Organização Mundial do Comércio (OMC) e outras organizações públicas e privadas, nacionais, regionais e transnacionais. Os relatórios do Clube de Roma também revelam o predomínio dessa perspectiva de análise:

O sistema político global compreende um conjunto específico de relações concernentes a uma escala de determinados problemas envolvidos na consecução, ou busca organizada, da atuação coletiva em nível global. Envolve a administração de uma rede de relações centrada nas articulações entre a unidade líder e os que buscam ou lutam por liderança. [...] As unidades que estruturam a interação de política global são as potências mundiais. Estas estabelecem as condições da ordem no sistema global. Elas são as mais capazes e dispostas a agir. Organizam e mantêm coalizões e estão presentes em todas as partes do mundo, habitualmente mobilizando forças de alcance global. Suas ações e reações definem o estado da política em nível global. [...] O sistema mundial é uma orientação para que se possa visualizar os arranjos sociais mundiais em termos de totalidade. Permite pesquisar as relações entre as interações de alcance mundial e os arranjos sociais em níveis regional, nacional e local. (Modelski, 1987, pp. 7-9 e 20)

O que predomina nos estudos, relatórios, diagnósticos e prognósticos sistêmicos é uma visão sincrônica da realidade, tomada como um todo ou em seus aspectos sociais, econômicos, políticos, demográficos, geopolíticos ou outros. As análises orientam-se principalmente no sentido de propiciar a inteligência da ordem 
socioeconômica mundial vigente, tendo em conta o seu funcionamento, a sua integração, os seus impasses e o seu aperfeiçoamento.

Nesse mundo sistêmico, são muitos, diversos, integrados e desencontrados os subsistemas mais ou menos relevantes: corporações transnacionais, Estados nacionais, entidades regionais, organizações multilaterais, mercados nacionais, regionais e mundiais, redes de informática, corporações da mídia, organizações religiosas, campanhas de publicidade, fundações destinadas ao incentivo e à problematização da pesquisa científica e tecnológica. São muitos os subsistemas ou sistemas menores que, além de funcionarem segundo uma dinâmica própria, inserem-se também na dinâmica de outros sistemas mais ou menos complexos ou abrangentes. Eles podem conjugar-se ou atritar-se, modificar-se ou recriar-se, em geral segundo exigências da dinâmica do capitalismo, com o sistema global.

Qualquer fato que ocorre em qualquer lugar, no mundo atual, pode produzir muito rapidamente efeitos em outros lugares. Todas as partes do mundo estão crescentemente emaranhadas em um vasto processo. E é evidente, também, que muitos no mundo, ao menos muitos do seus líderes, parecem reconhecer isso. À primeira vista, afinal, por muito tempo pareceu surpreendente que populações indígenas devessem realizar demonstrações contra testes de armas nucleares no Sul do Pacífico; ou que o governo da China devesse interessar-se pela guerra entre árabes e Israel. Alguns dos motivos para este novo sentido de interconexão mundial baseiam-se na ideologia e outros simplesmente na comunicação e informação mais rápida; mas algo mais fundamental também está em causa. Trata-se da difusão de uma idéia que esteve restrita às culturas de origem européia: a noção de que a vida humana e a condição do mundo podem ser indefinidamente aperfeiçoadas. (Roberts, 1990, p. 907)

Visto como um desafio epistemológico, a metateoria sistêmica sintetiza e desenvolve a lógica do funcionalismo, do estruturalismo e da cibernética. Pode ser vista como um produto sofisticado do pensamento pragmático, ou da razão instrumental.

Em geral, os estudos históricos privilegiam tanto a integração como a fragmentação, a diversidade e a desigualdade, a identidade e a alteridade, a ruptura e o impasse, o ciclo e a crise, a guerra e a revolução. A análise das relações, processos e estruturas que articulam e desenvolvem a transnacionalização, ou a globalização, compreende sempre a dominação política e a apropriação econômica, tanto quanto a formação, consolidação e crise de soberanias. No âmbito das configurações e dos movimentos da sociedade global, tanto se abrem novas perspectivas como se criam impasses insuspeitados sobre as condições e as possibilidades de construção da hegemonia, seja da nação, da classe social ou do bloco de poder. Em um mundo no qual as corporações transnacionais e as organizações multilaterais descolam-se dos territórios e fronteiras, navegando através e por sobre o mapa do mundo, criam-se desafios insuspeitados para a construção, o desenvolvimento ou a realização da soberania, hegemonia, democracia e cidadania. Muito do que parecia natural e evidente, ou possível e desejável, no âmbito da sociedade nacional pode tornar-se difícil, impossível ou simplesmente quimérico no âmbito da sociedade global. Sim, vista como realidade histórica, a globalização pode ser reconhecida como um palco no qual se atravessam permanentemente várias e muitas forças convergentes e desencontradas, que podem ser sintetizadas nas expressões integração e contradição.

Mais uma vez, em face dos desafios e horizontes que se colocam com as configurações e os movimentos da sociedade mundial, as ciências sociais são levadas a recuperar e a desenvolver o sentido de história, diacronia, ruptura, retrocesso, desenvolvimento, decadência, transformação, transfiguração. Ao lado do que parece ser estruturado, organizado, cibernético ou sistêmico encontrase a tensão, a fragmentação, a luta, a conquista, a dominação e a submissão, tanto quanto a raça e o povo, a mulher e o homem, o escravo e o senhor, a acumulação e o pauperismo, a alienação e a danação.

Vista como um desafio epistemológico, a metateoria histórica sintetiza e desenvolve a lógica da historicidade ativa nas relações, processos e estruturas de dominação e apropriação, ou integração e contradição, que se expressam no âmbito da reprodução ampliada do capital, bem como no âmbito do desenvolvimento desigual, contraditório e combinado, que se configura nos movimentos da globalização do capitalismo. Sob vários aspectos, a metateoria histórica pode ser vista como um produto sofisticado do pensamento dialético desenvolvido e 
sistematizado por Hegel e alguns dos seus continuadores, com a priorização da razão crítica:

Vivemos num mundo conquistado, desenraizado e transformado pelo titânico processo econômico e tecnocientífico do desenvolvimento do capitalismo, que dominou os dois ou três últimos séculos [...] As forças geradas pela economia tecnocientífica são agora suficientemente grandes para destruir o meio ambiente, ou seja, as fundações materiais da vida humana. As próprias estruturas das sociedades humanas, incluindo mesmo algumas fundações sociais da economia capitalista, estão na iminência de ser destruídas pela erosão do que herdamos do passado humano. Nosso mundo corre o risco de explosão e implosão. (Hobsbawm, 1995, p. 562)

Os cientistas sociais não precisam mais imaginar a realidade mundial para estudá-la, em seu todo ou em seus diferentes aspectos. Já é evidente que a transnacionalização, mundialização, planetarização ou, mais propriamente, globalização do mundo é uma realidade geoistórica, social, econômica, política e cultural. Uma realidade problemática, simultaneamente inquietante e fascinante, por suas implicações práticas e teóricas. É como se de repente os indivíduos e as coletividades se dessem conta de que fazem parte não somente da história universal, mas da humanidade. Reconhecendo que esta humanidade não se parece nem com a ideologia, nem com a utopia.

A história universal tem que ser construída e negada. À vista das catástrofes passadas e futuras, seria cinismo afirmar que na história se manifesta um plano universal que articula tudo em um nível mais amplo. Mas nem por isso deve ser negada a unidade que solda os fatores descontínuos, caoticamente dispersados, e as fases da história: o estágio da dominação sobre a natureza, a transição ao domínio sobre os homens e ao fim sobre a natureza interna. Não há uma história universal que oriente desde o selvagem ao humanitário; mas sim, da funda à superbomba. Seu fim é a ameaça total dos homens organizados pela humanidade organizada: a quintessência da descontinuidade [...] A história é a unidade da continuidade e descontinuidade. A sociedade não se conserva apesar de seu antagonismo, senão graças a ele. O interesse do lucro e, com ele, as relações de classe são o motor objetivo do processo produtivo de que depende a vida de todos; e cujo primado está orientado à morte de todos. (Adorno, 1975, p. 318)

Vistos em conjunto, os estudos sistêmicos e históricos revelam claramente o empenho das ciências sociais no sentido de interpretar o que vai pelo mundo, precisamente quando se verifica que já se pode realmente falar em "mundo mundo vasto mundo", ou quando se torna possível falar não só metafórica mas literalmente em "máquina do mundo". 1 .
Mais uma vez, como tem ocorrido em outras situações de ruptura histórica, as ciências sociais revelam-se formas de autoconsciência científica da realidade social. São desafiadas a interpretar fatos, situações, impasses e horizontes que se abrem a indivíduos e coletividades, povos e nações, tribos e nacionalidades. Revelam-se formas de autoconsciência mais ou menos sensíveis, minuciosas e abrangentes, integrativas e problemáticas, nas quais se taquigrafam, exorcizam, sublimam, cantam ou decantam condições e perspectivas de uns e outros, situados e volantes, nas configurações e nos movimentos da sociedade global.

\section{NOTA}

1 Alusão às imagens de Carlos Drummond de Andrade e Luis de Camões.

\section{BIBLIOGRAFIA}

ADORNO, Theodor W. (1975), Dialéctica negativa. Tradução de José Maria Ripalda. Madri, Taurus Ediciones.

ALBROW, Martin. (1990), "Globalization, knowledge and society", in Martin Albrow e Elizabeth King (eds.),Globalization, knowledge and society, Londres, Sage Publications, pp. 3-13.

COMISSÃO GULBENKIAN. (1996), Para abrir as ciências sociais. São Paulo, Cortez.

COX, Robert W. (1994), "Global restructuring: making sense of the changing international political economy", inRichard Stubbe e Geoffrey R.D. Underhill (eds.), Political economy and the changing global order, Londres, MacMillan, cap. 1, pp. 45-59. 
DURAND, Marie-Françoise, LEVY, Jacques e

RETAILLE, Denis. (1993), Le Monde: espaces et systèmes. Paris, Dalloz.

GREW, Raymond. (1993), "On the prospect of global history", in Bruce Mazlish e Ralph Buultjens (eds.), Conceptualizing global history, Oxford, Westview Press, cap.10, pp. 227-249.

HETTNE, Bjorn (org.). (1995), International political economy. Londres, Zed Books.

HOBSBAWM, Eric. (1995), A era dos extremos (o breve século XX: 1914-1991). Tradução de Marcos Santarrita. São Paulo, Companhia das Letras.

IANNI, Octavio. (1997), Teorias da globalização. $4^{\mathrm{a}}$ ed., Rio de Janeiro, Civilização Brasileira.

McGROW, Anthony G. (1992), "Conceptualizing global politics", in Anthony G. McGrow, Paul G. Lewis et al., Global politics, Cambridge, Polity Press, cap. 1, pp. 1-28.

MODELSKI, George. (1987), Long cycles in world politics. Seattle, University of Washington Press.

MOORE, Henrietta T. (1996), "The changing nature of anthropological knowledge", in Henrietta L. Moore (ed.),The future of anthropological knowledge, Londres, Routledge, cap. 1, pp. 1-15.

ORTIZ, Renato. (1994), Mundialização e cultura. São Paulo, Brasiliense.

PENNYCOOK, Alastair. (1994), The cultural politics of English as an international language. Londres, Longman.

ROBERTS, J.M. (1990), History of the world. Harmondsworth, Middlesex, Penguin Books.

ROBERTSON, Roland. (1992), Globalization. Londres, Sage Publications.
WALLERSTEIN, Immanuel. (1991), Unthinking social science. Cambridge, Polity Press. 